\title{
Increased $\mathrm{Ca}^{2+}$ signaling through $\mathrm{Ca}_{\mathrm{v}} 1.2$ promotes bone formation and prevents estrogen deficiency-induced bone loss
}

\author{
Chike Cao, ${ }^{1,2}$ Yinshi Ren, ${ }^{3}$ Adam S. Barnett, ${ }^{1}$ Anthony J. Mirando, ${ }^{3}$ Douglas Rouse, ${ }^{4}$ Se Hwan Mun, ${ }^{5}$ \\ Kyung-Hyun Park-Min, ${ }^{5}$ Amy L. McNulty, ${ }^{3}$ Farshid Guilak, ${ }^{6}$ Courtney M. Karner, ${ }^{3,7}$ \\ Matthew J. Hilton, ${ }^{3,7}$ and Ceoffrey S. Pitt ${ }^{1,2}$ \\ 'Ion Channel Research Unit, Duke University Medical Center, Durham, North Carolina, USA. ${ }^{2}$ Cardiovascular Research \\ Institute, Weill Cornell Medicine, New York, New York, USA. ${ }^{3}$ Department of Orthopaedic Surgery and ${ }^{4}$ Department of \\ Lab Animal Resources \& Rodent Surgical and Genetic Services, Duke University Medical Center, Durham, North Carolina, \\ USA. ${ }^{5}$ Arthritis and Tissue Degeneration Program, Hospital for Special Surgery, New York, New York, USA. ${ }^{6}$ Department of \\ Orthopaedic Surgery, Washington University Medical Center, St. Louis, Missouri, USA. ${ }^{7}$ Department of Cell Biology, Duke \\ University Medical Center, Durham, North Carolina, USA.
}

While the prevalence of osteoporosis is growing rapidly with population aging, therapeutic options remain limited. Here, we identify potentially novel roles for $\mathrm{Ca}_{\mathrm{v}} \mathbf{1 . 2} \mathrm{L}$-type voltage-gated $\mathrm{Ca}^{2+}$ channels in osteogenesis and exploit a transgenic gain-of-function mutant $\mathrm{Ca}_{\mathrm{v}} 1.2$ to stem bone loss in ovariectomized female mice. We show that endogenous $\mathrm{Ca}_{\mathrm{v}} 1.2$ is expressed in developing bone within proliferating chondrocytes and osteoblasts. Using primary BM stromal cell (BMSC) cultures, we found that $\mathrm{Ca}^{2+}$ influx through $\mathrm{Ca}_{v} 1.2$ activates osteogenic transcriptional programs and promotes mineralization. We used Prx1-, Col2a1-, or Col1a1-Cre drivers to express an inactivationdeficient $\mathrm{Ca}_{\mathrm{v}} 1.2$ mutant in chondrogenic and/or osteogenic precursors in vivo and found that the resulting increased $\mathrm{Ca}^{2+}$ influx markedly thickened bone not only by promoting osteogenesis, but also by inhibiting osteoclast activity through increased osteoprotegerin secretion from osteoblasts. Activating the $\mathrm{Ca}_{\mathrm{v}} 1.2$ mutant in osteoblasts at the time of ovariectomy stemmed bone loss. Together, these data highlight roles for $\mathrm{Ca}_{\mathrm{v}} 1.2$ in bone and demonstrate the potential dual anabolic and anticatabolic therapeutic actions of tissue-specific $\mathrm{Ca}_{v} 1.2$ activation in osteoblasts.

Conflict of interest: The authors have declared that no conflict of interest exists.

Submitted: June 5, 2017

Accepted: October 17, 2017

Published: November 16, 2017

Reference information:

JCI Insight. 2017;2(22):e95512.

https://doi.org/10.1172/jci.

insight. 95512

\section{Introduction}

$\mathrm{Ca}_{\mathrm{v}} 1.2$, an L-type voltage-gated $\mathrm{Ca}^{2+}$ channel, plays essential roles in many excitable cells, including neurons, smooth and cardiac muscle cells, and endocrine cells (1). Upon membrane depolarization, $\mathrm{Ca}^{2+}$ influx through the activated $\mathrm{Ca}_{\mathrm{v}} 1.2$ channel triggers a wide range of physiological processes, such as excitation-contraction coupling in cardiac muscle cells, graded contraction in smooth muscle cells of the vasculature and gut, hormone secretion in endocrine tissue, postsynaptic responses in various neurons, and activation of gene expression paradigms across a variety of tissues. Common to all of these examples is that the excitable cells in which they occur support frequent and dynamic changes in membrane potential that facilitate activation of the voltage-gated $\mathrm{Ca}_{\mathrm{v}} 1.2$ channel. In contrast, roles for $\mathrm{Ca}_{\mathrm{v}} 1.2$ signaling in nonexcitable cells are not well understood, but a gain-of-function mutation (G406R) in the human CACNA1C gene, encoding the pore-forming $\alpha_{1 \mathrm{C}}$ subunit of $\mathrm{Ca}_{\mathrm{v}} 1.2$, causes Timothy syndrome (TS) (2) and reveals prominent but previously unappreciated roles for $\mathrm{Ca}_{\mathrm{v}} 1.2$ in nonexcitable tissue (3).

TS is a multisystem disorder marked by life-threatening cardiac arrhythmias and soft-tissue syndactyly. The G406R mutation in $\mathrm{Ca}_{\mathrm{v}} 1.2$ that causes TS reduces voltage-dependent inactivation, thus impairing channel closure and allowing more $\mathrm{Ca}^{2+}$ influx into the cell. This increased $\mathrm{Ca}^{2+}$ entry, and consequent delay of membrane repolarization, provides a clear rationale for the cardiac arrhythmias. How $\mathrm{Ca}_{\mathrm{v}} 1.2$ participates in limb development and specifically why the mutant channel causes syndactyly, however, are not known. Some other variably penetrant features of TS, such as craniofacial and dental abnormalities and delayed hair development, demonstrate that a broad array of tissues are affected by aberrant $\mathrm{Ca}^{2+}$ influx through $\mathrm{Ca}_{\mathrm{v}} 1.2$ and reveal other unexpected but critical roles of $\mathrm{Ca}_{\mathrm{v}} 1.2$ in nonexcitable tissues. 
In a previous study, increased $\mathrm{Ca}^{2+}$ influx through the TS-mutant $\mathrm{Ca}_{\mathrm{v}} 1.2\left(\mathrm{Ca}_{\mathrm{v}} 1.2^{\mathrm{TS}}\right)$ channel in mandibular chondrocytes was shown in zebrafish and mouse models to recapitulate the macrognathia observed in TS patients (4). As the mandible is unique among skeletal elements in the skull to derive from endochondral ossification, we hypothesized that $\mathrm{Ca}_{\mathrm{v}} 1.2$ may influence bone development more broadly. Indeed, while plasma membranes of bone cells (e.g., osteoblasts) have not been shown to prominently display the voltage-dependent changes that control $\mathrm{Ca}_{\mathrm{v}} 1.2$ activity in excitable tissue, earlier reports identified functional L-type $\mathrm{Ca}^{2+}$ channels, mainly $\mathrm{Ca}_{\mathrm{v}} 1.2$, in human mesenchymal stem cells from BM cultured in osteogenic medium (5), in osteosarcoma cell lines (6), and in a rat osteoblast-like cell line (7). Further, $\mathrm{Ca}_{\mathrm{v}} 1.2$ was shown in an osteosarcoma cell line to be the primary site for $\mathrm{Ca}^{2+}$ influx, which promoted osteoblast differentiation $(8,9)$. In addition, $\mathrm{Ca}_{\mathrm{v}} 1.2$ expression and channel activity were regulated by calciotropic hormones such as $1,25(\mathrm{OH})_{2} \mathrm{D}_{3}(8,10)$ and parathyroid hormone (11), suggesting a functional contribution of $\mathrm{Ca}_{\mathrm{v}} 1.2 \mathrm{~L}$-type $\mathrm{Ca}^{2+}$ channel to bone development. More recently, a mutation in $C A C N A 1 C$ causing reduced current density through $\mathrm{Ca}_{\mathrm{v}} 1.2$ was associated with osteopenia (12).

Because $\mathrm{Ca}_{\mathrm{v}} 1.2$ is a well-characterized pharmacological target, for which antagonists are widely used to treat hypertension, angina, and cardiac arrhythmias, we set out to explore $\mathrm{Ca}_{\mathrm{v}} 1.2$ contributions to bone development and the consequent therapeutic potential of modulating $\mathrm{Ca}_{\mathrm{v}} 1.2$ activity in bone. We characterized the expression profile of $\mathrm{Ca}_{\mathrm{v}} 1.2$ during bone development and exploited $\mathrm{Ca}_{\mathrm{v}} 1.2^{\mathrm{TS}}$ transgenic mouse models to show that the gain-of-function $\mathrm{Ca}_{\mathrm{v}} 1.2^{\mathrm{TS}}$ promotes bone formation both during development and postnatally. We provide evidence that the augmented bone mass results from increased osteoblast differentiation and decreased osteoclast formation. With this foundation, we then demonstrated that activation of $\mathrm{Ca}_{\mathrm{V}} 1.2^{\mathrm{TS}}$ expression in osteoblasts reduced bone loss in an ovariectomy-induced (OVX-induced) osteoporosis mouse model.

\section{Results}

$\mathrm{Ca}_{V} 1.2$ is expressed during mouse bone development. To determine whether $\mathrm{Ca}_{\mathrm{v}} 1.2$ contributes to bone development, we first examined endogenous $\mathrm{Ca}_{\mathrm{v}} 1.2$ expression in developing limbs by using a $\mathrm{Ca}_{\mathrm{v}} 1.2$ reporter mouse (B6.129P2-Cacnalctm1Dgen $/ \mathrm{J}, \mathrm{Ca} 1.2^{+/ l a c z}$ ) in which a lacZ cassette (with a nuclear localization signal) disrupts the Cacnalc locus. While complete $\mathrm{KO}$ of Cacnalc is embryonic lethal due to inadequate cardiac output, $\mathrm{Ca}_{V} 1.2^{+/-}$mice are viable and fertile without obvious differences in any aspect of development (13) and only minor differences in morphology (4). The lacZ expression in $C a_{V} 1.2^{+/ l a c Z}$ mice thereby provides an accurate picture of the temporospatial $\mathrm{Ca}_{\mathrm{v}} 1.2$ expression pattern during development and definitive identification of $\mathrm{Ca}_{\mathrm{v}} 1$.2-expressing cells. We performed X-gal staining on frozen sections of long bones from early postnatal mice (P10), in which we observed strong staining in the resting and proliferating chondrocytes, but we did not detect staining in the hypertrophic chondrocytes (Figure 1, A-C). Expression was also strong in the perichondrium/periosteum (Figure 1, A and D), and extensive staining appeared in the lining cells of trabecular bones underneath the growth plate (Figure 1, A and E). At a later postnatal stage (P18), we also observed significant staining in the endosteum (Figure 1F). This staining pattern suggested that at least some of $\mathrm{Ca}_{\mathrm{v}} 1.2$ resides in osteoblast progenitors, which we further tested by examining expression in primary BM stromal cells (BMSCs) isolated from adult $C a_{V} 1.2^{+/ l a c Z}$ mice. $\mathrm{Ca}_{\mathrm{v}} 1.2$ expression as indicated by lacZ staining in these BMSCs (Figure 1G) - along with previously reported RNA sequencing data showing $\mathrm{Ca}_{\mathrm{v}} 1.2$ expression in osteoblasts and osteoblast progenitors (14), but not in the osteoclast lineage (15) - suggest important roles for $\mathrm{Ca}_{\mathrm{v}} 1.2$ in skeletogenesis.

Pharmacological inhibition of $\mathrm{Ca}_{V} 1.2$ channel activity decreased osteoblast differentiation. Based on the above expression patterns, we next asked whether $\mathrm{Ca}^{2+}$ influx through endogenous $\mathrm{Ca}_{\mathrm{v}} 1.2$ affected osteoblast differentiation. We performed an in vitro osteogenesis assay with BMSCs in the absence and presence of 2 different specific L-type $\mathrm{Ca}^{2+}$ channel blockers, diltiazem and nifedipine, applied to the cultures 12 hours before adding differentiation media. Cells were then cultured with the channel blocker or their diluents throughout the differentiation process. After 14 days of culture in osteogenic media, BMSCs treated with a channel blocker displayed substantially reduced mineralized nodule formation, as shown by von Kossa staining (Figure 1H). Quantitative PCR (qPCR) revealed that, in cells treated with the channel blocker, there was a marked decrease in transcripts of several osteoblast markers, including Alpl, Ibsp, and Bglap (Figure 1I). Together, these data suggest that $\mathrm{Ca}^{2+}$ signaling through endogenous $\mathrm{Ca}_{\mathrm{v}} 1.2$ regulates osteogenesis. 

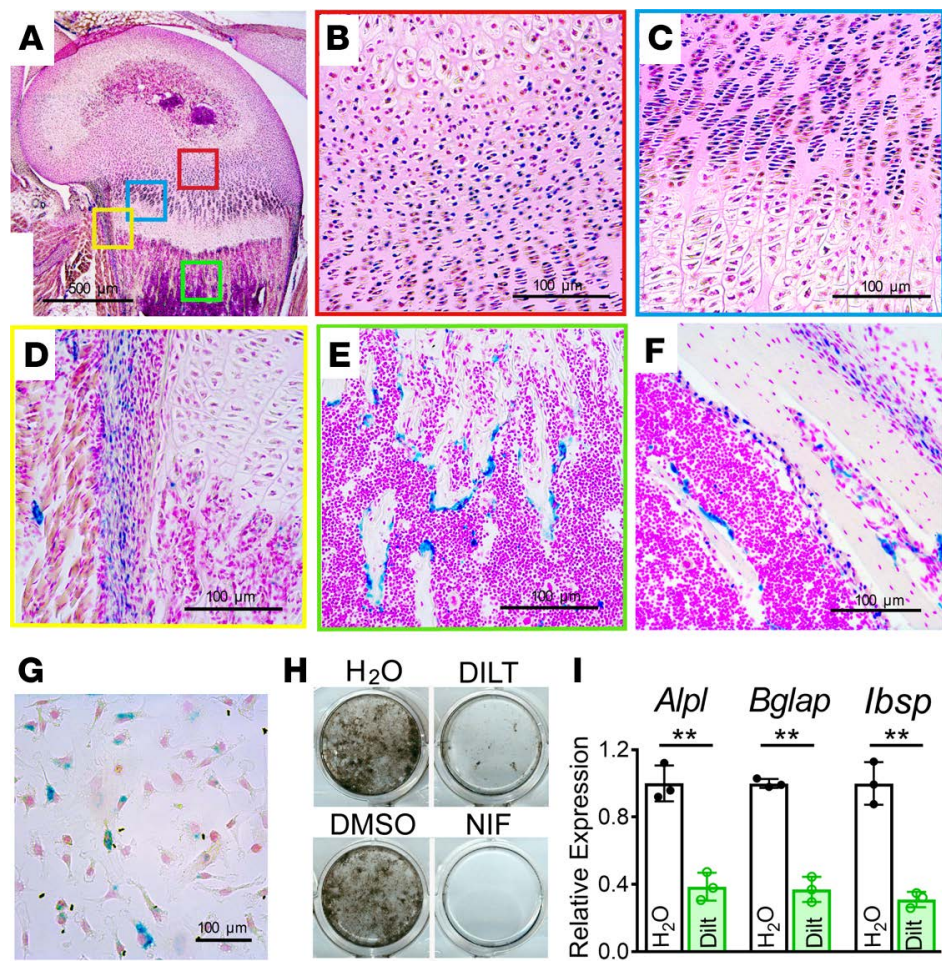

Figure 1. Endogenous $\mathrm{Ca}_{\mathrm{v}} 1.2$ is expressed during mouse endochondral ossification and in BMSCs, and pharmacological inhibition of $\mathrm{Ca}_{v} 1.2$ channel activity decreases osteoblast differentiation. (A) LacZ staining of $C a_{v} 1.2^{+/ l a c Z}$ femur at P10 at $5 \times$ magnification. (B-E) Boxed regions shown in $\mathbf{A}$ indicate the presence of $\mathrm{lac}^{+}$cells in the resting (B) and proliferating (C) chondrocytes, in the perichondrium/periosteum (D), and in the lining cells of trabecular bones (E). (F) LacZ staining of $C a_{v} 12^{+/ / a c z}$ tibia at $P 18$, showing lacZ staining in the endosteum. (G) LacZ staining of $\mathrm{Ca}_{v} 1.2^{+/ / a c z} \mathrm{BMSC}$ cultured for 6 days on coverslip in $\alpha$-MEM (without ascorbic acid) plus 15\% FBS and 1\% penicillin/streptomycin. (H) von Kossa staining of WT BMSCs after 14 days of differentiation in the presence of the L-type $\mathrm{Ca}^{2+}$ channel-specific blockers diltiazem $(10 \mu \mathrm{M})$ or nifedipine $(10 \mu \mathrm{M}), n \geq 3$. (I) Expression analysis of osteoblast markers by quantitative PCR of WT BMSCs after 9 days of differentiation in the absence and presence of diltiazem $(10 \mu \mathrm{M})$. Bar values are normalized means (normalized to $\mathrm{H}_{2} \mathrm{O}$ group) $\pm \mathrm{SD}\left(n=3,{ }^{* *} P<0.01\right)$. Statistical analysis was performed by 2 -tailed unpaired $t$ test.

Increased $\mathrm{Ca}^{2+}$ influx through $\mathrm{Ca}_{V} 1.2$ promotes bone formation in vivo. To explore whether $\mathrm{Ca}^{2+}$ signaling through $\mathrm{Ca}_{\mathrm{v}} 1.2$ in developing bone affects skeletogenesis in vivo, we exploited a transgenic mouse line in which a silenced TS mutant $\mathrm{Ca}_{\mathrm{v}} 1.2$ Cacna1c cDNA $\left(C a_{V} 1.2^{T S}\right)$ or a WT Cacnalc cDNA $\left(C a_{V} 1.2^{W T}\right)$ as a control had been knocked into the Rosa26 locus (Rosa26-Ca $1.2^{T S}$ and Rosa26-Ca $1.2^{W T}$, respectively). Expression of these cDNAs can be activated in a tissue-specific manner upon Cre recombinase-mediated excision of an upstream stop codon (16). We activated $C a_{V} 1.2^{T S}$ expression with Prx1-Cre targeting early mesenchymal stem cells (17), Col2a1-Cre targeting osteochondral progenitors (18), or Colla1-Cre targeting more mature osteoblast-lineage cells (19). At 6 weeks of age, mice in which $C a_{V} 1.2^{T S}$ expression was driven by Prx1-Cre showed profoundly increased bone mass in the appendicular skeleton and in the skull but not the axial skeleton - consistent with the restricted expression pattern of $\operatorname{Prx1}$ (20) - as detected by radiography and $\mu \mathrm{CT}$ when compared with their $\mathrm{Cre}^{-}$control littermates (Figure 2, A, C, and E). The combined distal femur cortical and trabecular bone volume (BV/TV) in Prx1-Cre; $\mathrm{Ca}_{V} 1.2^{T S}$ mice was increased by $>2$-fold compared with controls at 6 weeks of age (Figure 2D). $C a_{V} 1.2^{T S}$ expression driven by either Col2a1-Cre or Colla1-Cre produced an increased bone mass phenotype similar to that observed in Prx 1-Cre; $\mathrm{Ca}$ 1.2 $2^{T S}$ mice (Supplemental Figure 1, A, B, D and E; supplemental material available online with this article; https://doi.org/10.1172/jci.insight.95512DS1). Compared with the appendicular-restricted phenotype in the Prx1-Cre; $C a_{V} 1.2^{T S}$ mice, we observed increased bone mass in both the appendicular and axial skeleton (data not shown) in the Col2a1-Cre; $\mathrm{Ca}$ 1.2 $2^{T S}$ and Col1a1-Cre; $\mathrm{Ca} a_{V} 1.2^{T S}$ mice, however. These results are consistent with the broad expression pattern of Col2a1-Cre and Colla1-Cre throughout the skeleton. The high bone mass phenotype persisted at least to 12 months of age (data not shown) and resulted in almost complete obliteration of the BM cavity in long bones. Consistent with obliteration of the BM cavity and predicted extramedullary hematopoiesis, the $\mathrm{Ca}_{\mathrm{v}} 1.2^{\mathrm{TS}}$ mutant mice exhibited marked splenomegaly (Supplemental Figure 2). In contrast, mice expressing $C a_{V} 1.2^{W T}$ from Rosa26 driven by these 3 Cre lines displayed no difference in bone mass compared with their $\mathrm{Cre}^{-}$littermate controls, as shown by radiography or $\mu \mathrm{CT}$ (Figure 2B and Supplemental Figure 1, G-J). This latter observation suggests that expression of the noninactivating $\mathrm{Ca}_{V} 1.2^{T S}$ mutant channel - not just overexpression of $\mathrm{Ca}_{\mathrm{v}} 1.2$ - promotes increased bone mass in vivo. Alcian Blue Hematoxylin/Orange G (ABH/OG) staining confirmed that both primary and secondary ossification centers of $\mathrm{Ca}_{V} 1.2^{T S}$ mutant mice were occupied with excessive bone (Figure $2 \mathrm{~F}$ and Supplemental Figure 1, C and F). Extensive Alcian Blue-stained cartilage remnant was detected in the primary spongiosa under the growth plate of mutant mice (Figure 2F and Supplemental Figure 1, C and F). Moreover, the 
A
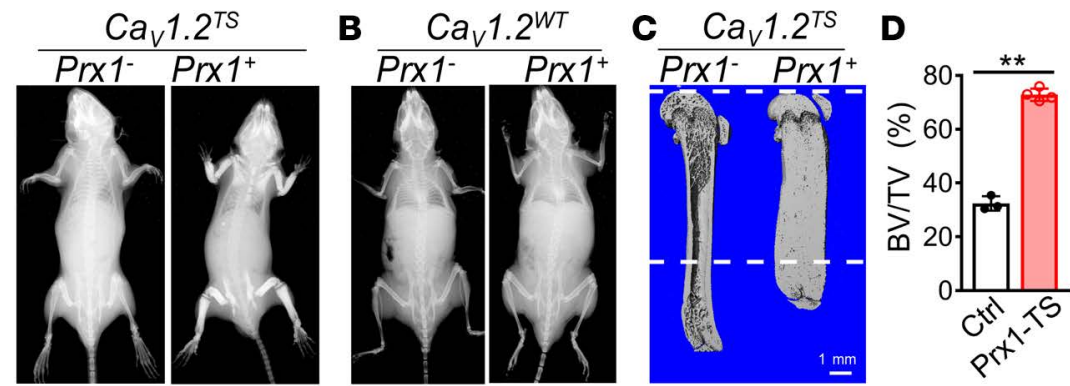

E

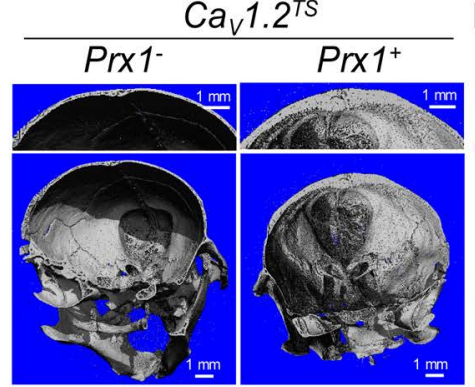

F
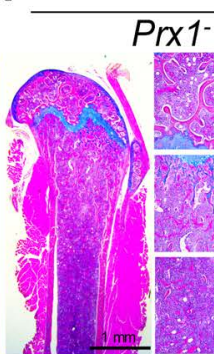

$C a_{V} 1.2^{T S}$
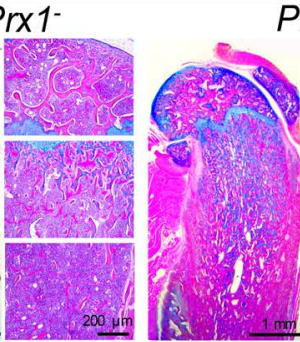

$\operatorname{Pr} \times 1^{+}$

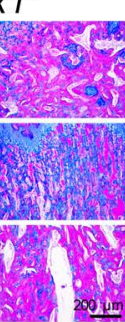

G

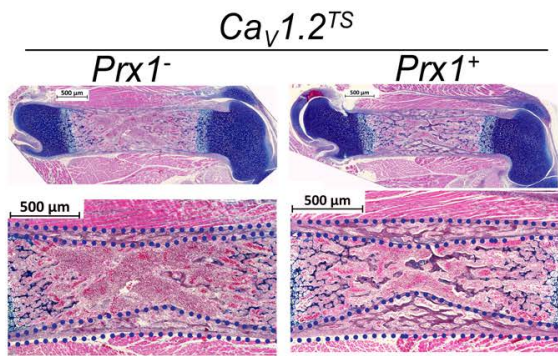

H

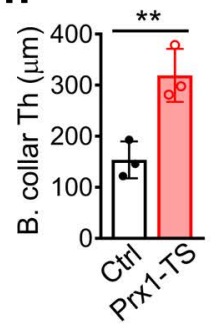

Figure 2. Expression of the $\mathrm{Ca}_{\mathrm{v}} 1.2^{\mathrm{TS}}$ channel increases bone mass in vivo. ( $A$ and $\mathbf{B}$ ) Radiographs of the whole bodies of 6-week-old $\mathrm{Cre}^{-} ; \mathrm{Ca}_{\mathrm{v}} 1.2^{\text {TS }}$ (control) and PrX1-Cre; $\mathrm{Ca}_{\mathrm{v}} 1.2^{\mathrm{TS}}$ (mutant) littermate mice. (C) $\mu$ CT 3-D reconstruction images of the femurs of 6-week-old $\mathrm{Cre}^{-} ; \mathrm{Ca}_{v} 1.2^{\text {TS }}$ (control, Prx1-) and Prx1-Cre; $\mathrm{Ca}_{\mathrm{v}} 1.2^{\text {TS }}$ (mutant, Prx1+) littermate mice. (D) $\mu$ CT analysis of BV/TV obtained from 800 slices (10- $\mu \mathrm{m}$ thick; $8 \mathrm{~mm}$ total) from the distal femur, a region indicated by the dashed lines in $\mathbf{C}$. Bar values are means $\pm \mathrm{SD}\left(n \geq 3,{ }^{* *} P<0.01\right)$. (E) $\mu \mathrm{CT} 3-\mathrm{D}$ reconstruction images of skulls of 6 -week-old $\mathrm{Cre}$

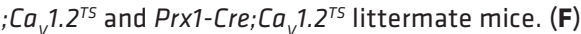
Alcian blue Hematoxylin/Orange $C$ (ABH/OG) staining of longitudinal femur sections from 6 -week-old $\mathrm{Cre}^{-} ; \mathrm{Ca}_{\mathrm{v}}{ }_{\mathrm{V}} 2^{\mathrm{TS}}$ and $\mathrm{Pr} \times 1-\mathrm{Cre} ; \mathrm{Ca}_{\mathrm{v}} \mathrm{C}^{\mathrm{TS}}$ littermate mice at $1.25 \times$ magnification. Shown to the right of the main images are $10 \times$ magnifications of the secondary ossification center (top), primary spongiosa (middle), and marrow region (bottom). (G) $\mathrm{ABH} /$ OC staining of longitudinal femur sections from $\mathrm{Cre}^{-} ; \mathrm{Ca}_{v} 1.2^{\text {TS }}$ and Prx1-Cre; $\mathrm{Ca}_{v}{ }^{1.2^{T S}}$ littermate mice at PO. (H) Analysis of bone collar thickness (B. collar Th) and percentage of bone area over tissue area (B. $\mathrm{Ar} / \mathrm{T}$. Ar) of femur diaphysis from $\mathrm{Cre}^{-} ; \mathrm{Ca}_{v} 1.2^{\text {TS }}$ and Prx1-Cre; $\mathrm{Ca}_{\mathrm{v}} 1.2^{\mathrm{TS}}$ littermate mice at P0. Bar values are means $\pm \operatorname{SD}\left(n=3 .{ }^{* *} P<0.01\right)$. Statistical analysis was performed by 2 -tailed unpaired $t$ test.

mutant bones lacked sculpting (Figure 2C and Supplemental Figure 1, A and D), indicating osteoclast defects (see below for further analysis).

Since the Prx 1-Cre driver activated $\mathrm{Ca}_{\mathrm{v}} 1.2^{\mathrm{TS}}$ expression during skeletal development, we next assessed whether we were able to detect the increase in bone mass in embryonic stage. Indeed, at P0, histology confirmed that Prx1-Cre; $\mathrm{Ca}$ 1.2 $2^{T S}$ femurs possessed a thicker bone collar and higher bone mass in the presumptive marrow cavity compared with littermate controls (Figure 2, G and $\mathrm{H}$ ).

Increased $\mathrm{Ca}^{2+}$ influx through $\mathrm{Ca}_{V} 1.2$ promotes osteoblast differentiation. To investigate further whether enhanced osteoblast function contributed to the increased bone mass, we performed dynamic histomorphometric analysis using calcein and alizarin red double labeling. Extensive green and red labeling was observed in the Prx1-Cre; $\mathrm{Ca}_{V} 1.2^{T S}$ mutant femur, in stark contrast to that in the control, indicating more active bone formation in $C a_{V} 1.2^{T S}$-expressing mice (Figure 3, A and B). A similar result was observed in Col2a-Cre; $\mathrm{Ca}_{V} 1.2^{T S}$ mutant femurs with calcein double labeling (Supplemental Figure 3, A and B).

To test the role of $\mathrm{Ca}_{\mathrm{v}} 1.2^{\mathrm{TS}}$ in osteogenesis directly, we performed osteoblast differentiation assays in vitro by isolating BMSCs from Rosa26-Ca $1.2^{T S}$ adult mice and infecting the cultured cells with adenovirus expressing either Cre recombinase (to remove the floxed STOP codon) or GFP as a control. von Kossa staining revealed widespread formation of mineralized nodules in $\mathrm{Ca}_{\mathrm{v}} 1.2^{\mathrm{TS}}$ expressing (infected with $C r e$ ) BMSCs after 10 days of differentiation, a time when there was limited mineralization in the control (infected with GFP) BMSCs (Figure 3C). We explored the mechanisms driving the accelerated mineralization in BMSCs expressing $\mathrm{Ca}_{\mathrm{v}} 1.2^{\mathrm{TS}}$ with $\mathrm{qPCR}$. This revealed markedly upregulated mRNA expression of 2 master osteogenic transcription factors, Runx2 and $S p 7$, in $\mathrm{Ca}_{\mathrm{v}} 1.2^{\mathrm{TS}}$-expressing BMSCs (Cre-infected) compared with control cells (GFP-infected) 48 hours after exposure to osteogenic differentiation media (Figure 3D). The increase persisted for the ensuing 15 days. Similarly, expression of Alpl, Ibsp , and Bglap transcripts was also elevated within 48 hours of differentiation in $\mathrm{Ca}_{\mathrm{v}} 1.2^{\mathrm{TS}}$-expressing BMSCs and remained significantly higher (compared with control) over the following 15 days (Figure 3D). Thus, these results indicate that expression of $\mathrm{Ca}_{\mathrm{v}} 1.2^{\mathrm{TS}}$ accelerated osteoblast differentiation of BMSCs in vitro. 


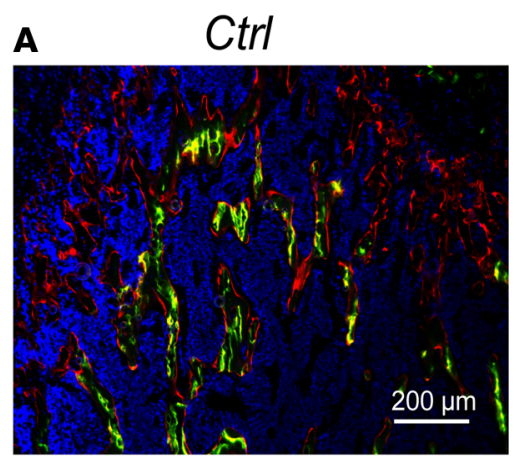

C

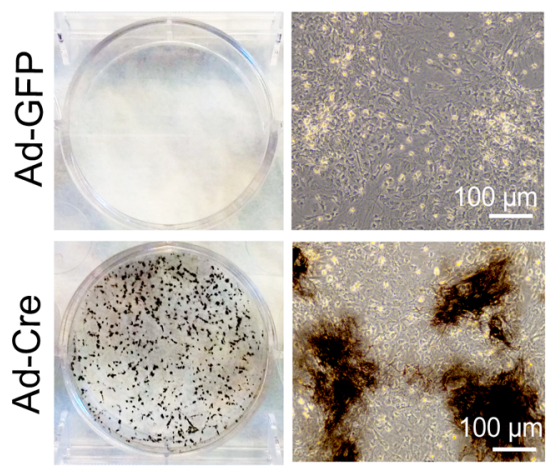

Alpl

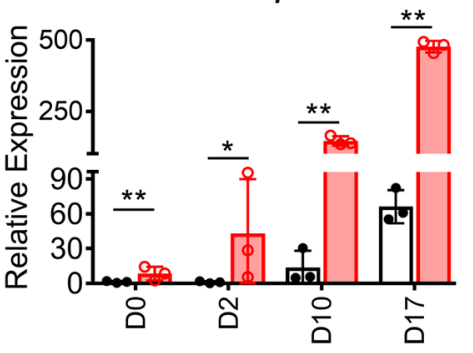

$\operatorname{Prx} 1^{+} ; \mathrm{Ca}_{V} 1.2^{\mathrm{TS}}$

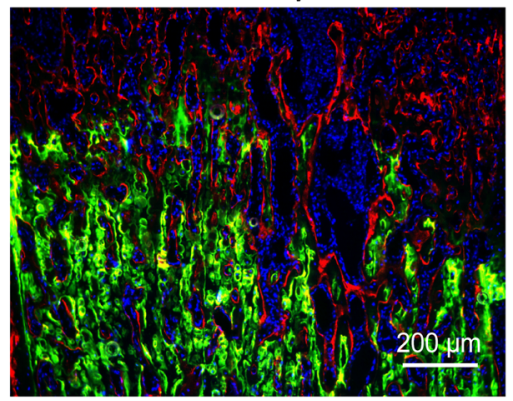

D

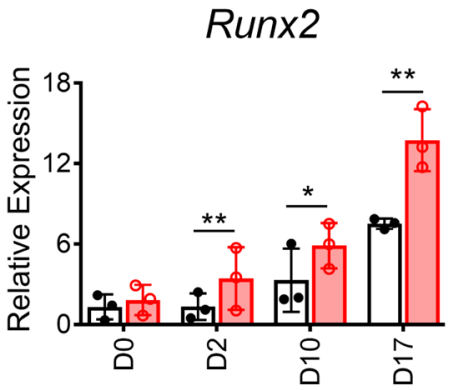

Ibsp

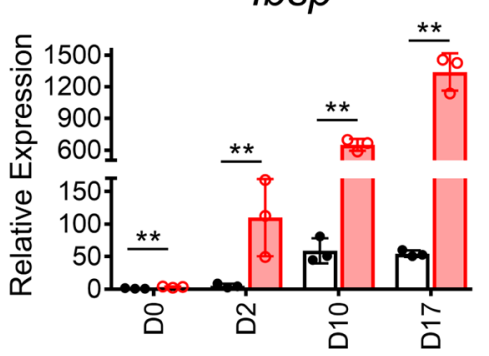

B

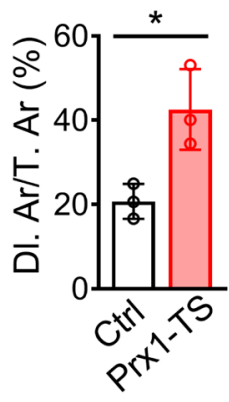

Ad-GFP
Ad-Cre

Sp7

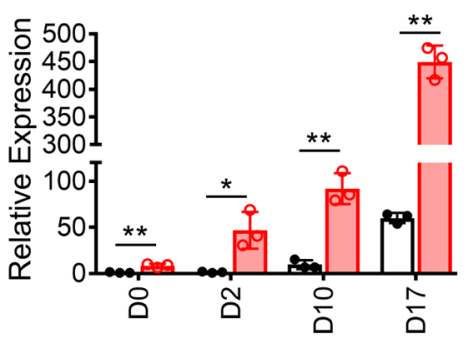

Bglap

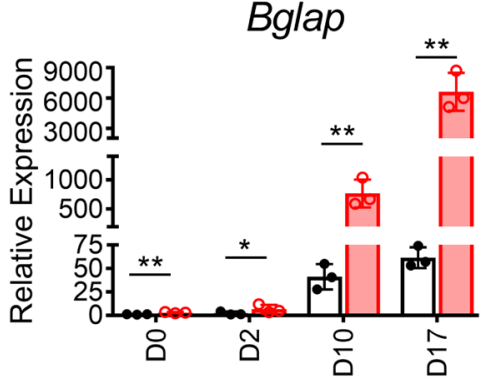

Figure 3. $\mathrm{Ca}_{\mathrm{v}} 1 \mathbf{2}^{\mathrm{TS}}$ channel promotes osteoblast differentiation. (A) Representative images of calcein and alizarin red double labeling in femurs from 6-week-old control $\mathrm{Cre}^{-} ; \mathrm{Ca}_{v} 1.2^{T S}$ and Prx1-Cre; $\mathrm{Ca}_{v} 1.2^{T S}$ littermate mice. (B) Analysis of the percentage of double-labeling area over tissue area underneath the growth plate (DI. $\mathrm{Ar} / \mathrm{T}$. Ar) in control $\mathrm{Cre}{ }^{-} ; \mathrm{Ca}_{v} 1.2^{T S}$ (Ctrl) and Prx1-Cre; $\mathrm{Ca} v 1.2^{T S}$ (Prx1-TS) littermate mice. Bar values are means $\pm \mathrm{SD}\left(n=3 .{ }^{*} P<0.05\right)$. (C) von Kossa staining of control (Ad-GFP) versus $\mathrm{Ca}_{v}$. $2^{T S}$-expressing (Ad-Cre) BMSCs after 10 days of differentiation, $n \geq 3$. (D) Expression analysis by quantitative PCR of control (Ad-GFP) versus $\mathrm{Ca}_{v} 1.2^{\mathrm{TS}}$-expressing (Ad-Cre) BMSCs at DO (6 hours of differentiation) or after 2,10 and 17 days (D2, D10, and D17) of differentiation. Bar values are means \pm SD ( $n=$ 3. ${ }^{*} P<0.05$ and $\left.{ }^{* *} P<0.01\right)$. Statistical analysis was performed by 2 -tailed unpaired $t$ test, and a $P$ value less than 0.05 was considered significant.

$C a_{V} 1.2^{T S}$ channel blocks osteoclast differentiation. The lack of sculpting of $\mathrm{Ca}_{V} 1.2^{T S}$ mutant long bones and the excessive cartilage remnant in the mutant primary spongiosa prompted us to hypothesize that osteoclast defects also contributed to the increased bone mass in $\mathrm{Ca}_{V} 1.2^{T S}$ mutant bones. To test this hypothesis, we performed tartrate-resistant acid phosphatase (TRAP) staining on femurs from 6-week-old mice. We observed substantially fewer osteoclasts in $\mathrm{Ca}_{V} 1.2^{T S}$-expressing mice compared with littermate controls (Figure 4A and Supplemental Figure 3C). Quantitative analysis showed that osteoclast number per tissue area (Oc. N/T. Ar) was decreased by 55\% and osteoclast area per tissue area (Oc. Ar/T. Ar) decreased by 54\% in Prx1-Cre; $\mathrm{Ca}_{V} 1.2^{T S}$ mice (Figure 4B). A similar phenotype was also observed in Col2a1-Cre; $\mathrm{Ca}_{V} 1.2^{T S}$ mice (Supplemental Figure 3, D and E), indicating reduced osteoclastogenesis in $C a_{V} 1.2^{T S}$ mutant mice. As Prx1-Cre, Col2a1-Cre, and Col1a1-Cre do not target the osteoclast lineage, we hypothesize that $\mathrm{Ca}_{\mathrm{v}} 1.2^{\mathrm{TS}}$ interfered with osteoblast-mediated osteoclastogenesis through the osteoprotegerin/RANKL (OPG/ RANKL) pathway. We tested this by measuring serum OPG, an inhibitor of RANKL, and observed a $34 \%$ increase of OPG in Prx $1-C r e ; C a_{V} 1.2^{T S}$ and a $27 \%$ increase in Col2a1-Cre; $C a_{V} 1.2^{T S}$ transgenic mice 
A

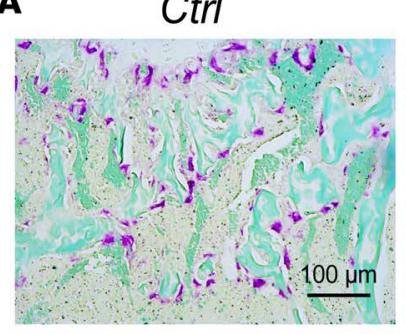

$\operatorname{Prx}^{+} ; \mathrm{Ca}_{V} 1.2^{\mathrm{TS}}$

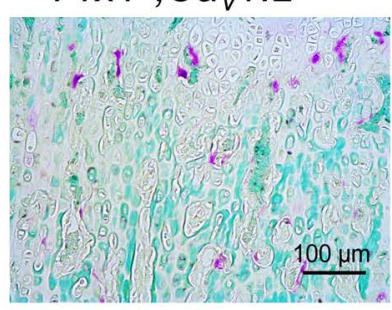

B

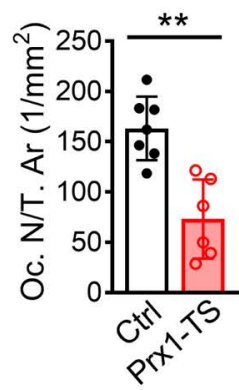

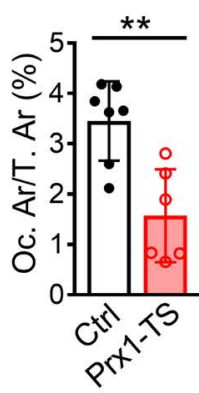

$\mathbf{F}$

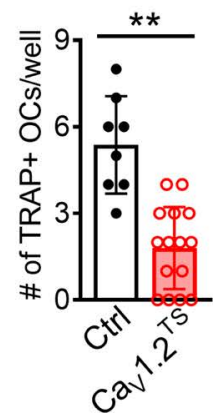

Figure 4. $\mathrm{Ca}_{\mathrm{v}} \mathbf{1 . 2 ^ { \mathrm { Ts } }}$ channel decreases osteoclast differentiation. (A) Representative images of TRAP staining in femur sections from 6-week-old control $\left(\mathrm{Cre}^{-} ; \mathrm{Ca}_{\mathrm{v}} 1.2^{T S}\right)$ and Prx1-Cre; $\mathrm{Ca}_{v} 1.2^{T S}$ littermate mice. (B) Analysis of osteoclast number (Oc. N) or osteoclast area (Oc. Ar) over tissue area (T. Ar) underneath the growth plate. Bar values are means $\pm \operatorname{SD}\left(n \geq 6 .{ }^{* *} P<0.01\right)$. (C) Serum OPG levels of control Cre $; a_{v} 1.2^{T S}$ and $P r \times 1-C r e ; C a_{v} 1.2^{T S}$ littermate mice at 6 weeks old. Bar values are means $\pm \mathrm{SD}\left(n=7\right.$. $\left.{ }^{* *} P<0.01\right)$. (D) Expression analysis of Rankl/Opg mRNA ratio by qPCR of control (Ad-GFP) versus Ca $1.2^{\top \mathrm{TS}}$-expressing (Ad-Cre) BMSCs after 8 days (D8) of differentiation. Bar values are means \pm SD $\left(n=3\right.$. $\left.{ }^{*} P<0.05\right)$. (E) Representative images of TRAP-stained cells in cocultures of BMMs and control $\left(\mathrm{Cre}^{-} ; \mathrm{Ca}_{\mathrm{v}} 1.2^{\mathrm{TS}}\right)$ or $\mathrm{Ca}_{\mathrm{v}} 1.2^{\mathrm{TS}}$-expressing $\left(\mathrm{Sp7}-\mathrm{Cre} ; \mathrm{Ca}_{\mathrm{v}} \mathrm{1} \cdot 2^{\mathrm{TS}}\right)$ calvarial osteoblasts in the presence of $10 \mathrm{nM} 1,25-\mathrm{dihy}$ droxyvitamin $D_{3}$ and $1 \mu \mathrm{m}$ prostaglandin $\mathrm{E}_{2}, n=3$. (F) Analysis of the number of TRAP-positive cells per well. Bar values are means \pm SD ( $n \geq 10$. ${ }^{* *} P<0.01$ ). Statistical analysis was performed by 2 -tailed unpaired $t$ test, and a $P$ value less than 0.05 was considered significant.

(Figure 4C and Supplemental Figure 3C). We further examined whether $\mathrm{Ca}_{\mathrm{v}} 1.2^{\mathrm{TS}}$ affects the Rankl/Opg (Tnfs11/Tnfrsf11b) mRNA expression ratio in primary BMSC cultures after activating $\mathrm{Ca}_{\mathrm{v}} 1.2^{\mathrm{TS}}$ expression and found - consistent with the in vivo data - a $61 \%$ decrease in $\mathrm{Ca}_{\mathrm{v}} 1.2^{\mathrm{TS}}$-expressing BMSCs (Figure 4D). Additionally, we cocultured BM-derived macrophages (BMMs) with $\mathrm{Ca}_{\mathrm{v}} 1.2^{\mathrm{TS}}$-expressing or WT calvarial osteoblasts in the presence of 1,25-dihydroxyvitamin D3 and prostaglandin $\mathrm{E}_{2}$ and observed less TRAP-positive osteoclasts with osteoblasts expressing the $\mathrm{Ca}_{\mathrm{v}} 1.2^{\mathrm{TS}}$ than with WT osteoblasts (Figure 4, E and $\mathrm{F}$ ), suggesting that $\mathrm{Ca}_{\mathrm{v}} 1.2^{\mathrm{TS}}$ expressed in cells of osteoblast lineage blocks osteoclastogenesis.

Postnatal expression of $\mathrm{Ca}_{V} 1.2^{\text {TS }}$ channel in Sp7-lineage cells enhances accrual of trabecular bone and prevents estrogen deficiency-induced bone loss. Having shown that $\mathrm{Ca}_{\mathrm{v}} 1.2^{\mathrm{TS}}$ expression enhances bone formation, we tested whether we could exploit $\mathrm{Ca}_{\mathrm{v}} 1.2^{\mathrm{TS}}$ expression to stimulate bone formation postnatally. We generated a doxycycline-inducible $S p 7-C r e ; C a_{V} 1.2^{T S}$ line by crossing the floxed-STOP Rosa26-Ca $1.2^{T S}$ with an inducible $S p 7$-Cre recombinase (Sp7-tTA;TetO-EGFP-Cre) (21). We blocked Cre expression with doxycycline-impregnated food until mice were 2 months old, then we removed doxycycline to activate $\mathrm{Ca}_{\mathrm{v}} 1.2^{\mathrm{TS}}$ and analyzed the long bones 8 weeks later. $\mu$ CT 3-D reconstruction of the distal femur metaphysis revealed a marked increase in trabecular bone in $C a_{V} 1.2^{T S}$-expressing mice (Supplemental Figure 4A). Quantitative measurement showed that BV/TV was increased by $56 \%$ in $\mathrm{Sp} 7-\mathrm{Cre} ; \mathrm{Ca}_{V} 1.2^{T S}$ male mice after activating $\mathrm{Ca}_{\mathrm{v}} 1.2^{\mathrm{TS}}$ expression for 8 weeks. This increase in bone acquisition was characterized by significant increase in trabecular thickness (Tb.Th) and trabecular number (Tb.N), whereas trabecular bone separation (Tb.Sp) was unaffected (Supplemental Figure 4B).

We then tested whether expression of $\mathrm{Ca}_{\mathrm{v}} 1.2^{\mathrm{TS}}$ in postnatal bone could prevent estrogen deficiency-induced bone loss in female mice. We performed OVX on 2-month-old $\mathrm{Sp} 7-\mathrm{Cre} ; \mathrm{Ca}_{V} 1.2^{T S}$ mice or their $\mathrm{Cre} ; \mathrm{Ca}_{V} 1.2^{T S}$ littermate controls and induced $\mathrm{Ca}_{\mathrm{v}} 1.2^{\mathrm{TS}}$ expression by removing doxycycline at the time of surgery. Simultaneous sham operation on the control $\left(\mathrm{Cre} ; \mathrm{Ca}_{V} 1.2^{T S}\right.$ littermates) allowed us to monitor the effects of OVX in the absence of activating $\mathrm{Ca}_{\mathrm{v}} 1.2^{\mathrm{TS}}$. At 4 months old, the growth plates of the distal femur and the length of the humerus were 
A

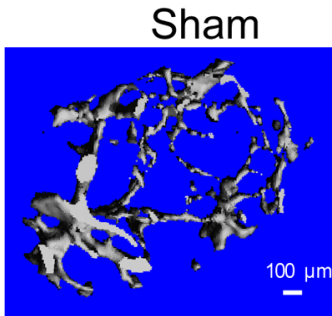

B

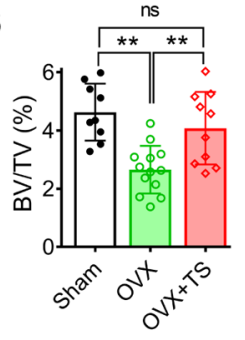

C

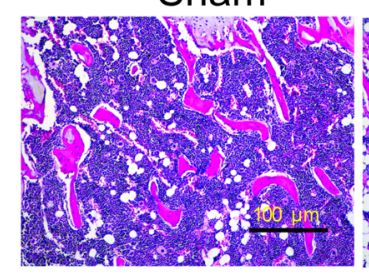

D

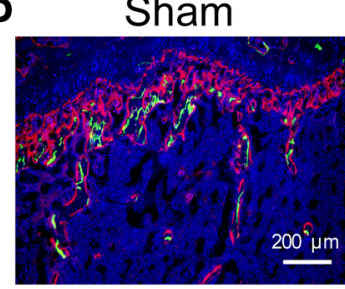

E

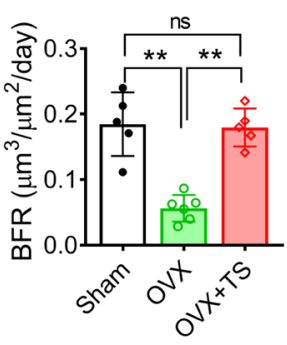

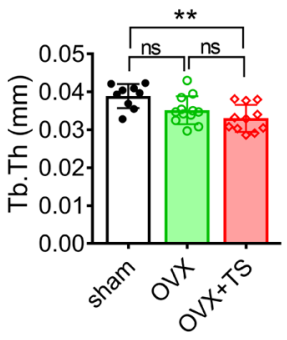

OVX

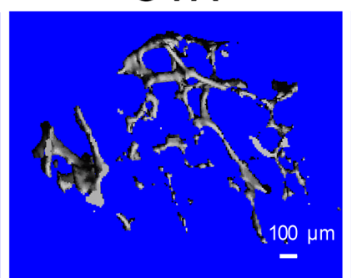

OVX+TS

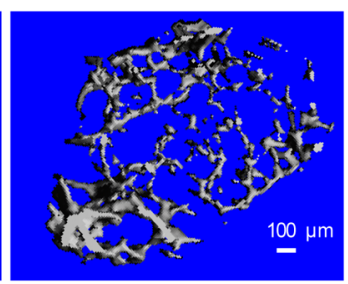

OVX
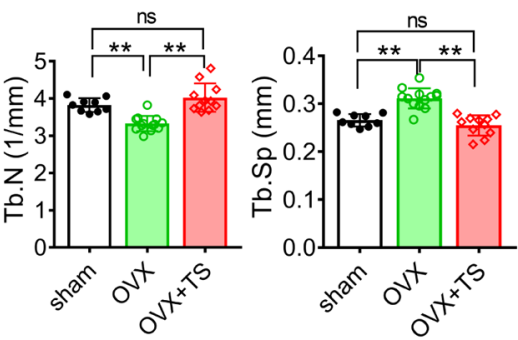

OVX+TS
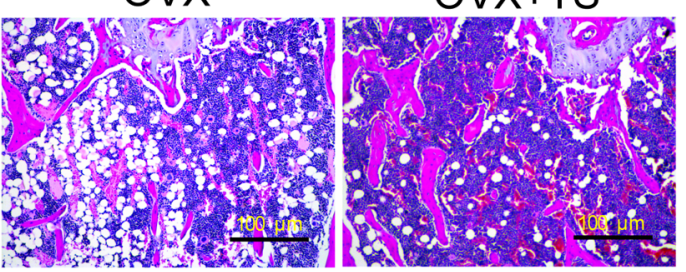

OVX
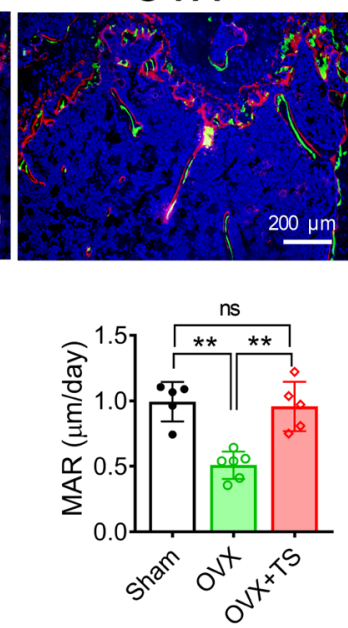

OVX+TS
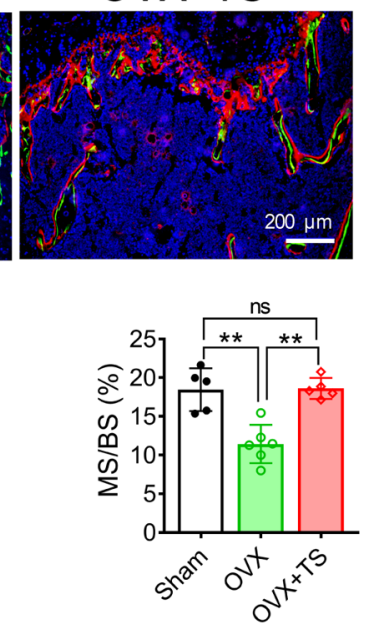

Figure 5. $\mathrm{Ca}_{\mathrm{v}} 1.2^{\mathrm{TS}}$ prevents estrogen deficiencyinduced bone loss. (A) $\mu C T$ 3-D reconstruction images of metaphyses of distal femurs of mice 8 weeks after sham surgery, ovariectomy [OVX], and OVX with $C a_{v} 1.2^{T S}$ expression (Sp7-Cre; $\left.\mathrm{Ca}_{v} 1.2^{T S}\right)$. (B) Analysis of bone volume density (BV/TV), trabecular thickness (Tb.Th), trabecular number (Tb.N), and trabecular spacing (Tb. $\mathrm{Sp}$ ) of metaphyses of distal femurs of mice 8 weeks after sham surgery, OVX, or OVX with $C a_{v} 1.2^{\text {TS }}$ expression $\left(5 p 7-C r e^{+} ; C a_{v} 1.2^{T S}\right)$. Bar values are means $\pm \mathrm{SD}(n \geq$ 8. ${ }^{* *} P<0.01$ ). (C) H\&E staining of mice 8 weeks after sham surgery, OVX, or OVX with $C a_{v} 1 \cdot 2^{T S}$ expression $\left(\mathrm{Sp} 7-\mathrm{Cre} ;\left[a_{v} 1.2^{T S}\right)\right.$. (D) Representative images of calcein and alizarin red double labeling in the trabecular bones underneath the growth plate of mice 8 weeks after sham surgery, OVX, or OVX with $C a_{v} 1.2^{T S}$ expression $\left(\mathrm{Sp} 7-\mathrm{Cre} ;\left[a_{v} 1.2^{\mathrm{TS}}\right)\right.$. (E) Dynamic histomorphometry analysis of trabecular bones $1.5 \mathrm{~mm}$ away from the growth plate of mice 8 weeks after sham surgery, OVX, or OVX with $C a_{v} 1.2^{T S}$ expression ( $\left.5 p 7-C r e ; C a_{v} 1.2^{T S}\right)$. BFR, bone formation rate; MAR, mineral apposite rate; and MS/BS, percentage of mineralizing surface over bone surface. Bar values are means $\pm \operatorname{SD}\left(n \geq 8 .{ }^{*} P<0.05\right.$ and ${ }^{* *} P<$ $0.01)$. Statistical analysis was performed by one-way ANOVA followed by Tukey's post-test analysis, and a $P$ value less than 0.05 was considered significant.

normal in these mice (Supplemental Figure 5), suggesting that depleting estrogen or activating $\mathrm{Ca}_{\mathrm{v}} 1.2^{\mathrm{TS}}$ expression at the 2-month-old time point does not affect the growth plate and the longitudinal growth of long bones. In the Cre controls subject to OVX, we observed noticeable trabecular bone loss (compared with sham controls) 8 weeks after OVX (Figure 5A). Quantitative measurements showed that $43 \%$ of BV/TV was lost in control mice after OVX (Figure 5B), consistent with less trabecular bones shown in H\&E staining (Figure 5C). Compared with sham-operated control mice, the parameter $\mathrm{Tb}$. $\mathrm{Th}$ remained relatively constant in OVX mice throughout the 8-week experimental period, while Tb.N decreased and Tb.Sp increased after OVX surgery (Figure 5B), indicating that OVX can induce loss of trabecular bone by perforation and division, as seen in previous OVX experiments $(22,23)$. Dynamic histomorphometric analysis showed that bone formation rate (BFR) was decreased by $71 \%$, mineral apposition rate (MAR) was decreased by $49 \%$, and the percentage of mineralizing surface over bone surface (MS/BS) was decreased by $38 \%$ in the control group after OVX (Figure 5, D and E), indicating reduced osteoblast function after estrogen deficiency at 2 months of age. In contrast, activation of $C a_{V} 1.2^{T S}$ (by removing doxycycline) at the time of surgery effectively mitigated bone loss and maintained bone mass after OVX (BV/TV, $4.25 \% \pm 0.54 \%$ ) to the same level as that in the sham-operated controls (BV/TV, 4.49\% $\pm 0.33 \%$ ) (Figure 5, A and B). The preservation of bone mass in activated $C a_{V} 1.2^{T S}$ mice after OVX was accompanied by maintenance of Tb.N and Tb.Sp compared with control sham mice (Figure $5 \mathrm{~B}$ ). Consistent with these data, we confirmed by H\&E staining that OVX $\mathrm{Ca}_{V} 1.2^{T S}$ mice maintained trabecular bone in femurs similar to control sham mice and stemmed trabecular bone loss compared with OVX control mice (Figure 5C). The maintenance of bone mass after OVX in the $\mathrm{Ca}_{\mathrm{v}} 1.2^{\mathrm{TS}}$-expressing bones was in part due to sustained osteoblast function, as dynamic histomorphometric analysis showed that BFR, MAR, and MS/BS were unaffected in $C a_{V} 1.2^{T S}$ mutant femurs after OVX compared with control sham mice and were significantly higher than control OVX mice (Figure 5, D and E). 


\section{Discussion}

This study revealed unexpected roles for the $\mathrm{Ca}_{\mathrm{v}} 1.2$ voltage-gated $\mathrm{Ca}^{2+}$ channel in bone development and remodeling and uncovered consequences of increased $\mathrm{Ca}^{2+}$ influx through the channels. Using conditional mouse models and the BMSC culture system, we demonstrated that expression of a transgenic $\mathrm{Ca}_{\mathrm{v}} 1.2^{\mathrm{TS}}$ mutant channel promotes bone formation and inhibits bone resorption during skeletal development, homeostasis, and osteoporotic contexts. Actions of voltage-gated L-type $\mathrm{Ca}^{2+}$ channels were previously reported in osteosarcoma cell lines $(6,8,24)$, and a previous immunohistochemical study suggested the presence of $\mathrm{Ca}_{\mathrm{v}} 1.2$ in developing bones (25). Our data, exploiting a definitive $\mathrm{Ca}_{\mathrm{v}} 1.2$ signal from a mouse in which lac $Z$ was knocked into the Cacnalc gene, reveal the endogenous $\mathrm{Ca}_{\mathrm{v}} 1.2$ expression pattern and avoid nonspecific signals that can arise from detection by antibodies. With this approach, we observed prominent endogenous $\mathrm{Ca}_{\mathrm{v}} 1.2$ expression in the developing perichondrium/periosteum, endosteum, and growth plate, which all give rise to osteoprogenitors. We did not detect $\mathrm{Ca}_{\mathrm{v}} 1.2$ in the marrow cavity, as was suggested by one study using an immunohistochemical approach (25) but not by another (26). Further, we observed the consequences of activating $\mathrm{Ca}_{\mathrm{v}} 1.2^{\mathrm{TS}}$ expression in vivo. Thus, these data extend previous findings for a $\mathrm{Ca}_{\mathrm{v}} 1.2$ role in mandibular development (4) and highlight additional unexpected roles for $\mathrm{Ca}_{\mathrm{v}} 1.2$ $\mathrm{Ca}^{2+}$ channels in nonexcitable tissue.

It is intriguing that, in the growth plate, we observed $\mathrm{Ca}_{\mathrm{v}} 1.2$ expression in the proliferating chondrocytes but not hypertrophic chondrocytes. One resulting hypothesis is that termination of $\mathrm{Ca}_{\mathrm{v}} 1.2$ expression (and the resulting downstream $\mathrm{Ca}^{2+}$ signaling) is required for the transition of proliferating chondrocytes to a hypertrophic state. Consistent with this hypothesis is our observation that bones expressing $\mathrm{Ca}_{\mathrm{v}} 1.2^{\mathrm{TS}}$ are shorter: in $\mathrm{Ca}_{\mathrm{v}} 1.2^{\mathrm{TS}}$-expressing mice in which $\mathrm{Ca}_{\mathrm{v}} 1.2^{\mathrm{TS}}$ was driven by Prx1-Cre or Col2a1-Cre - both of which target chondrocyte lineages - a delay in chondrocyte maturation may reduce the ultimate length of the long bones.

Because these mouse models all employed Cre recombinases that drove $\mathrm{Ca}_{\mathrm{v}} 1.2^{\mathrm{TS}}$ expression in osteoblast lineages, and not in osteoclasts or their precursors, we conclude that the observed anticatabolic responses resulted from an increase in the Rankl/Opg expression ratio and OPG secretion and consequent extrinsic inhibition of osteoclastogenesis. This is consistent with previous data showing that $\mathrm{Ca}_{\mathrm{v}} 1.2$ regulates OPG secretion (27) and the well-defined roles for $\mathrm{Ca}_{\mathrm{v}} 1.2$ channels in promoting hormone secretion from endocrine tissue. Moreover, our lacZ expression data showed that $\mathrm{Ca}_{\mathrm{v}} 1.2$ is expressed within bone tissue where osteoblast precursor cells reside, and previous RNA-seq data showed no expression of $\mathrm{Ca}_{\mathrm{v}} 1.2$ in murine BMMs or during osteoclast differentiation (15).

Our data showing upregulation of 2 master osteogenic transcription factors, Runx2 and $S p 7$, after expression of $C a_{V} 1.2^{T S}$ suggest that increased $\mathrm{Ca}^{2+}$ influx through the noninactivating mutant $\mathrm{Ca}_{\mathrm{v}} 1.2$ channel augments signaling cascades that promote osteoblast differentiation and mineralization. Moreover, the reduced mineralization observed in BMSC cultures treated with $\mathrm{Ca}_{\mathrm{v}} 1.2$ blockers highlights the physiologic contribution of $\mathrm{Ca}^{2+}$ influx through endogenous $\mathrm{Ca}_{\mathrm{v}} 1.2$ channels in osteoblast precursors. Nevertheless, we cannot exclude the possibility that $\mathrm{Ca}^{2+}$-independent signaling through $\mathrm{Ca}_{\mathrm{v}} 1.2^{\mathrm{TS}}$ contributes to the $\mathrm{Ca}_{\mathrm{v}} 1.2^{\mathrm{TS}}$-induced increase in bone formation. Two previous studies reported that the mutant $\mathrm{Ca}_{\mathrm{v}} 1.2^{\mathrm{TS}}$ channel activates $\mathrm{Ca}^{2+}$-independent downstream signaling pathways in neurons or hair follicles, as suggested by experiments showing that expression of a "pore-dead" $\mathrm{Ca}_{\mathrm{v}} 1.2^{\mathrm{TS}}$ channel recapitulated the $\mathrm{Ca}_{\mathrm{v}} 1.2^{\mathrm{TS}}$ channel effects $(28,29)$. Based on observations regarding the role of $\mathrm{Ca}_{\mathrm{v}} 1.2$ in mandibular development - in which a $\mathrm{Ca}^{2+}$-permeant WT or $\mathrm{Ca}_{\mathrm{v}} 1.2^{\mathrm{TS}}$ mutant channel, but not a pore-dead channel, successfully rescued abnormal development after $\mathrm{Ca}_{\mathrm{v}} 1.2$ knockdown - we propose that $\mathrm{Ca}^{2+}$ influx through $\mathrm{Ca}_{\mathrm{v}} 1.2$ is essential for bone development.

Our data showing that activating a transgenic, overexpressed $\mathrm{Ca}_{\mathrm{v}} 1.2^{\mathrm{TS}}$ channel during embryogenesis or postnatally increases bone mass and prevents bone loss secondary to estrogen deficiency do not likely have implications for TS patients, who have a mutant, endogenous CACNA1C locus present throughout development and beyond. Rather, the consistent results obtained by activating a $\mathrm{Ca}_{\mathrm{v}} 1.2^{\mathrm{TS}}$ channel specifically with Prx1-Cre, Col2a1-Cre, or Col1a1-Cre suggest that increasing $\mathrm{Ca}^{2+}$ influx through a noninactivating $\mathrm{Ca}_{\mathrm{v}} 1.2$ channel in any osteoblast lineage cell promotes bone formation by increasing osteoblast differentiation and inhibiting osteoclast differentiation. The dual effect of transgenic $\mathrm{Ca}_{\mathrm{v}} 1.2^{\mathrm{TS}}$ suggests a possible therapeutic strategy for osteoporotic or osteopenic conditions. The majority of current osteoporosis treatments are anticatabolic agents that reduce osteoclast bone resorption, such as estrogens, bisphosphates, and calcitonin $(30,31)$. These anticatabolics (especially bisphosphonates) are associated with gastrointestinal problems, osteonecrosis of 
the jaw, and atypical femur fractures or fragility fractures. Therefore, our approach here is more in line with anabolic therapies such as recombinant human parathyroid hormone (rhPTH) (32) and more recently developed agents demonstrating dual roles (e.g., romosozumab) that show increasing promise (33). Further, the increased bone accrual postnatally observed with the inducible Sp7-Cre model highlights the potential for the development of bone-targeted $\mathrm{Ca}_{\mathrm{v}} 1.2$ agonists, starting with lead compounds such as BayK-8644 or FPL 64176, for anabolic and anticatabolic skeletal effects, as observed in our $\mathrm{Ca}_{\mathrm{v}} 1.2^{\mathrm{TS}}$ mice.

\section{Methods}

Experimental mouse models. $C a_{V} 1.2^{+/ L a c Z}$, Rosa26-Ca $1.2^{T S}$, and Rosa26-Ca $1.2^{W T}$ mouse lines have been described previously $(4,16)$. Homozygous Rosa26-Ca $1.2^{T S}$ or Rosa26-Ca $1.2^{W T}$ mice were crossed with the transgenic Prx1-Cre (17), Col2a1-Cre (18), or 2.3Col1a1-Cre (19) mice. All skeletal analyses were performed on 6-week-old mice unless otherwise specified. For serum OPG assay (R\&D Systems), serum was collected from 6-week-old mice without fasting following the manufacturer's instructions.

To generate inducible mouse models for investigating postnatal bone formation and remodeling, we crossed Rosa26-Ca $1.2^{T S}$ mice with Sp7-Cre (B6.Cg-Tg [Sp7-tTA, tetO-EGFP/cre] 1Amc/J; The Jackson Laboratory) (21). Breeders and their pups were maintained on a rodent diet containing $625 \mathrm{mg} / \mathrm{kg}$ doxycycline (Harlan) to suppress Cre recombinase expression in the embryonic and early postnatal stages. Chow was replaced with regular rodent diet (no doxycycline) to induce $C r e$ expression when mice were 2 months old. For OVX experiments, OVX or sham operation were performed on 2-month-old female mutant $\left(\mathrm{Sp} 7-\mathrm{Cre} ; \mathrm{Ca}_{V} 1.2^{T S}\right)$ and control $\left(\mathrm{Cre} ; \mathrm{Ca}_{V} 1.2^{T S}\right)$ mice under isofluorane anesthesia. The doxycycline diet was replaced with regular rodent diet on the same day of OVX or sham surgery. Tissue was collected for analysis 8 weeks after OVX.

Chemicals. All chemicals were obtained from MilliporeSigma unless otherwise indicated.

$X$-gal staining. X-gal (5-bromo-4-chloro-3-indolyl- $\beta$-D-galactopyranoside) staining was performed on frozen tissue sections. Forelimbs or hindlimbs were fixed in $4 \%$ paraformaldehyde on ice for 20 minutes (embryos) or 1 hour (postnatal stage), decalcified with $14 \%$ EDTA at $4^{\circ} \mathrm{C}$, processed to $30 \%$ sucrose, and snap-frozen embedded with OCT compound (Sakura Finetek). Frozen sections (10 $\mu \mathrm{m}$-thick) were refixed in ice-cold $1 \times$ PBS with $2 \%$ paraformaldehyde, $0.2 \%$ glutaraldehyde, $2 \mathrm{mM} \mathrm{MgCl}, 0.2 \%$ Tween- 20 , and $30 \%$ sucrose for 10 minutes and stained with X-gal staining solution $(5 \mathrm{mM}$ potassium ferrocyanide, $5 \mathrm{mM}$ potassium ferricyanide, $1 \mathrm{mg} / \mathrm{ml}$ X-gal, $2 \mathrm{mM} \mathrm{MgCl}_{2}, 0.1 \%$ sodium deoxycholate, and $0.2 \%$ IGEPAL CA-630 in dark for $24-48$ hours at $37^{\circ} \mathrm{C}$. Specimens were counterstained with Nuclear Fast Red. For X-gal staining on BMSCs, the staining was performed for 48 hours at $37^{\circ} \mathrm{C}$.

$X$-ray radiography and $\mu C T$ analysis of mice. X-ray radiographic images of the hindlimbs were acquired using a Faxitron X-ray system (Faxitron Bioptics) at $31 \mathrm{kV}$ for 9 seconds. For $\mu \mathrm{CT}$ scanning, the specimens were fixed in $10 \%$ neutral buffered formalin and then fitted in a $50 \mathrm{ml}$ centrifuge tube with $70 \%$ ethanol. Images were obtained with a Scanco VivaCT 80 scanner (Scanco Medical AG) set to $55 \mathrm{kVp}$ and $145 \mu \mathrm{A}$, voxel size $10.4 \mu \mathrm{m}$. To quantify trabecular bone parameters, $50 \mu \mathrm{CT}$ slices $(\sim 0.5 \mathrm{~mm}$ total $)$ immediately below the distal growth plate of the femur were analyzed.

Double labeling and cryosectioning. For dynamic histomorphometry, mice were injected i.p. with calcein and alizarin-3-methyliminodiacetic acid (MilliporeSigma) at $20 \mathrm{mg} / \mathrm{kg}$ and $40 \mathrm{mg} / \mathrm{kg}$, respectively, on days 8 and 2 prior to euthanasia. Femurs were extracted and fixed in $10 \%$ neutral buffered formalin for 24 hours. After washing with $1 \times$ PBS, nondecalcified femurs were processed to $30 \%$ sucrose and OCT embedding, and they were sectioned at $10 \mu \mathrm{m}$ using Leica Cryostat equipped with Cryojane (Leica). The slides were counterstained with DAPI. Dynamic histomorphometry was performed with OsteoMeasure commercial software.

Histology and TRAP staining. For histology, decalcified samples were processed for paraffin embedding and then sectioned at $6-\mu \mathrm{m}$ thickness. H\&E, ABH/OG, and TRAP staining were performed following standard protocols.

Mouse BMSC isolation and culture, viral infection, and osteoblast differentiation. BMSCs were isolated aseptically from the femurs and tibias of 6- to 10-week-old Rosa26-Ca $1.2^{T S}$ or WT mice and were plated in $\alpha$-MEM without ascorbic acid (Thermo Fisher Scientific) with 15\% FBS (Hyclone) and 1\% penicillin/ streptomycin (Invitrogen) at $37^{\circ} \mathrm{C}$ in a $5 \% \mathrm{CO}_{2}$ humidified incubator. After 48 hours of adhesion, the media was changed to remove nonadherent cells. BMSCs reached confluency after an additional 4 days of culture with a single media change. Cells were passaged with $0.25 \%$ trypsin-EDTA digestion (Invitrogen) and reseeded at $3 \times 10^{5}$ cells/6-well or $1 \times 10^{5}$ cells/12-well for mineralization assays. 
For viral infections, cells at 70\% confluency were infected with adenovirus expressing either GFP or Cre-recombinase (Baylor College of Medicine, Houston, Texas, USA) at a multiplicity of infection (MOI) of 50 in serum-containing medium for 24 hours. Seventy-two hours after viral infection, BMSCs were cultured in osteogenic media ( $\alpha$-MEM containing 15\% FBS, $1 \%$ penicillin/streptomycin, $50 \mu \mathrm{g} / \mathrm{ml} \mathrm{L}$-ascorbic acid [MilliporeSigma] and $10 \mathrm{mM} \beta$-glycerophosphate [MilliporeSigma]). For von Kossa staining, cells were fixed in methanol on ice for 20 minutes, rinsed with distilled water, and exposed to $365 \mathrm{~nm}$ ultraviolet light in 5\% silver nitrate solution (MilliporeSigma) for 2 minutes.

Coculture osteoclastogenesis assay. Primary calvarial osteoblasts were isolated from P0 to P2 $\mathrm{Cre} ; \mathrm{Ca}_{V} 1.2^{T S}$ (control) or $\mathrm{Sp} 7-\mathrm{Cre} ; \mathrm{Ca}_{V} 1.2^{T S}$ pups. The calvaria were digested in $1 \times \mathrm{PBS}$ containing $0.18 \%$ collagenase $\mathrm{P}$ (Roche Diagnostics) for 10 minutes at $37^{\circ} \mathrm{C}$ with vigorous shaking. The digestion was repeated 4 times, and the cells isolated from the last 3 digestions were combined. The isolated osteoblasts $\left(5 \times 10^{3}\right.$ cells/well $)$ were seeded in a 96-well plate with $200 \mu 1$ of $\alpha$-MEM containing $15 \%$ FBS and $1 \%$ penicillin/streptomycin in $5 \% \mathrm{CO}_{2}$ at $37^{\circ} \mathrm{C} 2$ days before starting the coculture. Twenty-four hours after adhesion, the medium was changed to osteogenic media. BMMs were isolated from BM of WT C57BL/6J mice and cultured on a $100-\mathrm{mm}$ culture dish after lysis of the RBC with $\alpha$-MEM containing $15 \% \mathrm{FBS}, 1 \%$ penicillin/streptomycin, and $5 \mathrm{ng} / \mathrm{ml}$ of M-CSF for 24 hours. Nonadherent cells were collected, washed once with $1 \times$ PBS, resuspended in osteogenic media with addition of $10 \mathrm{nM}$ of 1,25 -dihydroxyvitamin $\mathrm{D}_{3}$ and $1 \mu \mathrm{m}$ of prostaglandin $\mathrm{E}_{2}$, and added to the wells of the 96-well plate containing the calvarial osteoblasts. The coculture was observed for 6-9 days, and half of the media was changed every other day until the appearance of giant osteoclasts. To visualize osteoclasts, cells were fixed and processed for TRAP staining.

Real-time PCR. Total RNA was isolated from BMSCs using RNAeasy mini kit (Qiagen). Total RNA (1 $\mu \mathrm{g}$ ) was reverse transcribed to cDNA using iScript Reverse Transcription Supermix (Bio-Rad). qPCR was performed using SYBR green Supermix (Bio-Rad). Gene expression was first normalized to GAPDH and then normalized to control samples. The primers for Runx2, Sp7, Alpl, Bglap, and Ibsp were previously described (34). The primers for Gapdh are: forward, 5' - AGTAACACCACGGAGGGGG - 3'; reverse, 5' - GGTCTGATCACAGGGCATGG - 3'. The primers for Opg (Tnfrsf11b) are: forward, 5' - CCGAGGACCACAATGAACAAGT - 3'; reverse, 5' - CTGGGTTGTCCATTCAATGATG - 3'. The primers for Rankl (Tnfs11) are: forward, 5' - CTGGGCCAAGATCTCTAACATGA - 3'; reverse, 5' - GGTACGCTTCCCGATGTTTC - 3'.

Statistics. Statistical analyses were performed using GraphPad Prism 7.0. Two-tailed unpaired $t$ tests were used for 2 conditions, and 1-way ANOVA with Tukey's post-test analysis was applied for multipe comparisons. $P$ $<0.05$ was considered statically significant. Data are represented as mean \pm SD from $n \geq 3$ experiments. qPCR assays were performed with 3 independent RNA isolates. Viral transfections were repeated $n \geq 3$. Fold changes were calculated by dividing the value of the treatment group by the value of the control group at the same time point. Increasing or decreasing percentage changes were calculated by dividing the value of difference between the treatment group and control group by the value of the control group and then multiplying 100 .

Study approval. All mouse protocols were approved by the IACUC at Duke University.

\section{Author contributions}

CC designed research, conducted experiments, acquired data, analyzed data, and wrote the manuscript; YR conducted experiments; ASB designed research, conducted experiments, acquired data, and analyzed data; AJM conducted experiments; DR conducted experiments; SHM acquired data and analyzed data; KHPM, ALM, and FG analyzed data; CMK, MJH, and GSP designed research, analyzed data, and wrote the manuscript.

\section{Acknowledgments}

This work was supported by NIH NIAMS R01 AR063071 to MJH; a Duke Chancellor's Discovery Award, a Harrington Discovery Institute/Harrington Scholar-Innovator grant, and NIH NICHD R01 HD090132 to GSP. We thank Matthew Greenblatt (Weill Cornell) for helpful suggestions.

Address correspondence to: Matthew J. Hilton, 308 Research Drive, LSRC Building Room B321C, Duke University, Durham, North Carolina 27708, USA. Phone: 919.613.9761; Email: matthew.hilton@dm.duke.edu. Or to: Geoffrey S. Pitt, 413 East $69^{\text {th }}$ Street, Belfer Research Building Room 502, Weill Cornell Medicine, New York, New York 10021, USA. Phone: 646.962.7641; Email: geoffrey.pitt@med.cornell.edu. 
1. Catterall WA. Structure and regulation of voltage-gated Ca2+ channels. Annu Rev Cell Dev Biol. 2000;16:521-555.

2. Hatanaka T, Hatanaka Y, Tsuchida J, Ganapathy V, Setou M. Amino acid transporter ATA2 is stored at the trans-Golgi network and released by insulin stimulus in adipocytes. J Biol Chem. 2006;281(51):39273-39284

3. Splawski I, et al. $\mathrm{Ca}(\mathrm{V}) 1.2$ calcium channel dysfunction causes a multisystem disorder including arrhythmia and autism. Cell. 2004;119(1):19-31.

4. Ramachandran KV, et al. Calcium influx through L-type CaV1.2 Ca2+ channels regulates mandibular development. J Clin Invest. 2013;123(4):1638-1646.

5. Zahanich I, Graf EM, Heubach JF, Hempel U, Boxberger S, Ravens U. Molecular and functional expression of voltage-operated calcium channels during osteogenic differentiation of human mesenchymal stem cells. J Bone Miner Res. 2005;20(9):1637-1646.

6. Guggino SE, Lajeunesse D, Wagner JA, Snyder SH. Bone remodeling signaled by a dihydropyridine- and phenylalkylamine-sensitive calcium channel. Proc Natl Acad Sci USA. 1989;86(8):2957-2960.

7. Morain P, Peglion JL, Giesen-Crouse E. Ca2+ channel inhibition in a rat osteoblast-like cell line, UMR 106, by a new dihydropyridine derivative, S11568. Eur J Pharmacol. 1992;220(1):11-17.

8. Caffrey JM, Farach-Carson MC. Vitamin D3 metabolites modulate dihydropyridine-sensitive calcium currents in clonal rat osteosarcoma cells. J Biol Chem. 1989;264(34):20265-20274.

9. Liu R, Li W, Karin NJ, Bergh JJ, Adler-Storthz K, Farach-Carson MC. Ribozyme ablation demonstrates that the cardiac subtype of the voltage-sensitive calcium channel is the molecular transducer of 1, 25-dihydroxyvitamin $\mathrm{D}(3)$-stimulated calcium influx in osteoblastic cells. J Biol Chem. 2000;275(12):8711-8718.

10. Bergh JJ, Shao Y, Puente E, Duncan RL, Farach-Carson MC. Osteoblast $\mathrm{Ca}(2+)$ permeability and voltage-sensitive Ca(2+) channel expression is temporally regulated by 1,25-dihydroxyvitamin D(3). Am J Physiol, Cell Physiol. 2006;290(3):C822-C831.

11. Gu Y, Preston MR, Magnay J, E1 Haj AJ, Publicover SJ. Hormonally-regulated expression of voltage-operated Ca(2+) channels in osteocytic (MLO-Y4) cells. Biochem Biophys Res Commun. 2001;282(2):536-542.

12. Boczek NJ, et al. Novel Timothy syndrome mutation leading to increase in CACNA1C window current. Heart Rhythm. 2015;12(1):211-219.

13. Seisenberger $C$, et al. Functional embryonic cardiomyocytes after disruption of the L-type alpha1C (Cav1.2) calcium channel gene in the mouse. J Biol Chem. 2000;275(50):39193-39199.

14. Kemp JP, et al. Phenotypic dissection of bone mineral density reveals skeletal site specificity and facilitates the identification of novel loci in the genetic regulation of bone mass attainment. PLoS Genet. 2014;10(6):e1004423.

15. Lee J, et al. STAT5 is a key transcription factor for IL-3-mediated inhibition of RANKL-induced osteoclastogenesis. Sci Rep. 2016;6:30977.

16. Paşca SP, et al. Using iPSC-derived neurons to uncover cellular phenotypes associated with Timothy syndrome. Nat Med. 2011;17(12):1657-1662.

17. Logan M, Martin JF, Nagy A, Lobe C, Olson EN, Tabin CJ. Expression of Cre Recombinase in the developing mouse limb bud driven by a Prxl enhancer. Genesis. 2002;33(2):77-80.

18. Ovchinnikov DA, Deng JM, Ogunrinu G, Behringer RR. Col2a1-directed expression of Cre recombinase in differentiating chondrocytes in transgenic mice. Genesis. 2000;26(2):145-146.

19. Dacquin R, Starbuck M, Schinke T, Karsenty G. Mouse alpha1(I)-collagen promoter is the best known promoter to drive efficient Cre recombinase expression in osteoblast. Dev Dyn. 2002;224(2):245-251.

20. Martin JF, Olson EN. Identification of a prx1 limb enhancer. Genesis. 2000;26(4):225-229.

21. Rodda SJ, McMahon AP. Distinct roles for Hedgehog and canonical Wnt signaling in specification, differentiation and maintenance of osteoblast progenitors. Development. 2006;133(16):3231-3244.

22. Tanizawa $\mathrm{T}$, et al. Reduction in bone formation and elevated bone resorption in ovariectomized rats with special reference to acute inflammation. Bone. 2000;26(1):43-53.

23. Yamaura M, et al. Local bone turnover in the metaphysis of the proximal tibia and the lumbar vertebra during the early periods after ovariectomy in rats. Calcif Tissue Int. 1996;58(1):52-59.

24. Guggino SE, Wagner JA, Snowman AM, Hester LD, Sacktor B, Snyder SH. Phenylalkylamine-sensitive calcium channels in osteoblast-like osteosarcoma cells. Characterization by ligand binding and single channel recordings. J Biol Chem. 1988;263(21):10155-10161.

25. Shao Y, Alicknavitch M, Farach-Carson MC. Expression of voltage sensitive calcium channel (VSCC) L-type Cav1.2 (alpha1C) and T-type Cav3.2 (alpha1H) subunits during mouse bone development. Dev Dyn. 2005;234(1):54-62.

26. Wang XT, et al. Cardiac L-type calcium channel alpha 1-subunit is increased by cyclic adenosine monophosphate: messenger RNA and protein expression in intact bone. J Bone Miner Res. 2000;15(7):1275-1285.

27. Bergh JJ, Xu Y, Farach-Carson MC. Osteoprotegerin expression and secretion are regulated by calcium influx through the L-type voltage-sensitive calcium channel. Endocrinology. 2004;145(1):426-436.

28. Yucel G, et al. State-dependent signaling by Cav1.2 regulates hair follicle stem cell function. Genes Dev. 2013;27(11):1217-1222.

29. Krey JF, et al. Timothy syndrome is associated with activity-dependent dendritic retraction in rodent and human neurons. Nat Neurosci. 2013;16(2):201-209.

30. Reid IR. Anti-resorptive therapies for osteoporosis. Semin Cell Dev Biol. 2008;19(5):473-478.

31. Miller PD. Anti-resorptives in the management of osteoporosis. Best Pract Res Clin Endocrinol Metab. 2008;22(5):849-868.

32. Lane NE, Kelman A. A review of anabolic therapies for osteoporosis. Arthritis Res Ther. 2003;5(5):214-222.

33. Cosman F, et al. Romosozumab Treatment in Postmenopausal Women with Osteoporosis. NEngl J Med. 2016;375(16):1532-1543.

34. Chen J, Holguin N, Shi Y, Silva MJ, Long F. mTORC2 signaling promotes skeletal growth and bone formation in mice. $J$ Bone Miner Res. 2015;30(2):369-378. 